\title{
TRAYECTORIAS LABORALES DE MIGRANTES ENTRE ÁFRICA Y LATINOAMÉRICA: EL CASO DE LOS SENEGALESES EN ARGENTINA
}

\author{
Labor pathways of migrants between Africa and Latin America: \\ the case of Senegalese in Argentina
}

Resumen. En este artículo buscamos aportar una mirada antropológica a las prácticas laborales protagonizadas por migrantes senegaleses en Argentina. Abordamos ciertos procesos que concurren a dar forma y sentido al entramado laboral del que participan estas personas. Analizamos el rol de los agentes de control estatal que regulan sus prácticas laborales, los modos en que la prensa local los objetiva, así como las identificaciones étnicas de estos migrantes y su pertenencia a redes transnacionales. Desde un enfoque biográfico y transnacional concebimos las prácticas de los sujetos como estrategias de un "saber migrar" y "saber circular" (Arab, 2008). La metodología corresponde a un trabajo de campo etnográfico en el contexto de origen y destino de los migrantes. Aquí presentamos dos casos de trayectorias laborales.

Palabras clave: migrantes senegaleses, trayectorias laborales, transnacionalismo.

\begin{abstract}
In this paper, we intend to provide an anthropological perspective of the labour practices carried out by Senegalese migrants in Argentina. We address certain processes which contribute to give shape and meaning to the labour pathways of these people. We analyze the role of state control agents governing labour practices, the ways in which local media objectifies them, as well as the ethnic identifications and the belonging to transnational networks of these migrants. From a biographical and transnational approach, we conceive the practices of these people as strategies of a "know how to migrate" and "know how to circulate" (Arab, 2008). The methodology applied is an ethnographic fieldwork in the context of origin and destination of the migrants. Here we present two cases of labour pathways.
\end{abstract}

Keywords: Senegalese migrants, labour pathways, transnationalism.

División Etnografía, FCNyM, Universidade Nacional de La Plata. Buenos Aires, Argentina. E-mail: mluzespiro@gmail.com. Orcid: 0000-0001-8122-6981. 


\section{Introducción}

En este trabajo ${ }^{1}$ buscamos aportar una mirada antropológica sobre los itinerarios laborales protagonizados por migrantes senegaleses en algunas ciudades de Argentina. Al adentrarnos en la complejidad de este problema, se supera una observación preliminar que los asocia unívocamente con la venta ambulante, para identificar la multiplicidad de experiencias que viven estas personas en el mundo del trabajo, configuradas en los vaivenes de la economía política del contexto argentino actual (de retracción del consumo, embestida contra migrantes y crisis sindicales), en la desregulación del mercado laboral y su segmentación étnico-nacional (Castles, 2013).

En la investigación llevada adelante con migrantes senegaleses en las ciudades de La Plata y Puerto Madryn analizamos las prácticas y representaciones en el mundo del trabajo, para comprender los modos en que se construyen sus trayectorias laborales y se vertebran sus proyectos migratorios. Desde un trabajo etnográfico acompañamos los itinerarios que trazan estas experiencias, cuyos desenlaces, a modo de bifurcaciones, estancamientos, retrocesos o avances moldean esos proyectos.

Al considerarlos desde la perspectiva de los campos sociales transnacionales (Levitt, 2010), el contexto de origen senegalés es tomado en cuenta en el proceso de configuración de las trayectorias. Asimismo, cabe poner de relieve la lógica migratoria de circulación en la que se despliegan -propia de su forma de entender y estar en el mundo-, en base a la cual los migrantes senegaleses desarrollan capacidades para "saber-migrar" y "saber-circular", es decir, "para movilizar su red migratoria, su conocimiento y la implementación de estrategias alternativas para moverse, migrar y circular" (Arab, 2008, p. 21).

En esta oportunidad, retomamos argumentos propuestos en escritos anteriores en los que analizamos la construcción de representaciones y alterizaciones sobre los migrantes senegaleses y las identificaciones construidas por ellos, las formas de violencia institucional identificadas, así como las estrategias desplegadas para enfrentarlas, que concurren a dar forma y sentido a las trayectorias laborales que trazan dichos migrantes (Espiro, 2012; 2016a; 2016b; Espiro, Voscoboinik, Zubrzycki, 2016).

Desde la antropología norteamericana se entiende por trayectoria "a una línea de vida o carrera, a un camino a lo largo de toda la vida, que puede variar y cambiar en dirección, grado y proporción" (Elder, 2001, p. 63). Este no implica necesariamente una secuencia ni velocidades definidas porque las transiciones de posiciones que lo organizan pueden ser imprevisibles y simultáneas. También puede presentar puntos de inflexión que generen

Este trabajo está financiado por una Beca de posgrado UNLP, un proyecto PID N827 y un PICT 2017-1543. 
una discontinuidad en el mismo. El curso de vida o biografía se conforma a partir de la interdependencia de un "haz de trayectorias" que representan los diversos dominios en los que nos desenvolvemos a lo largo de nuestras vidas (trabajo, recreación, escolaridad, religión, familia, migración, etc.), pudiendo alguno de estos ámbitos primar por sobre el resto, organizando ciertos momentos del camino.

Entre las diversas nociones de trayectorias laborales, aquí seguimos desarrollos latinoamericanos y argentinos y las entendemos operativamente "como un particular entramado de experiencias laborales que tienen una orientación y direccionalidad, esto es una dinámica específica" (Lucero, 2003, p. 79). Apuntamos a reconstruir el encadenamiento longitudinal y contingente de sucesos laborales tomando en consideración el proceso de decisión llevado a cabo por los sujetos (Muñiz Terra, 2012). Desde esta perspectiva se afirma que:

Los recorridos laborales tienen lugar a través de coyunturas, forman parte de procesos, de tendencias a largo plazo. Al mismo tiempo, posibilita un análisis de las prácticas, estrategias y representaciones que desarrollan los actores a lo largo de su vida laboral, que pueden ocasionar alteraciones en la esfera macroestructural. (Roberti, 2012, p. 12)

La metodología cualitativa aplicada para este estudio corresponde a un trabajo de campo etnográfico con migrantes senegaleses en las ciudades de La Plata y Puerto Madryn, desde 2012 hasta 2018, y una estancia de campo de un mes en Senegal en 2017. De la diversidad de experiencias registradas en entrevistas en profundidad, conversaciones informales y observación participante con los diferentes interlocutores, en esta oportunidad presentamos dos casos de trayectorias laborales, a partir de las biografías de Billy y Bamba, que dialogan con las experiencias de otros "paisanos" suyos para nutrir y tensionar estos itinerarios. Lejos de estandarizar la variabilidad existente, apuntamos a comprender su complejidad. Ya que al analizar estos procesos desde el concepto de trayectorias laborales coincidimos con los autores que sostienen que "el relato de un individuo ilumina no sólo un caso particular, también es la expresión de una historia social colectiva" (Roberti, 2012, p. 6).

\section{Breve reseña de la migración senegalesa en Argentina}

Su llegada se registra desde mediados de la década de 1990 y se inscribe en una tendencia que rompe con sus destinos migratorios tradicionales. Su intensificación, a inicios de este siglo, se enmarca dentro del fenómeno de las migraciones sur-sur. El censo argentino de 2010 registra 459 personas de origen senegalés (INDEC, 2010), mientras que la Asociación de Senegaleses Residentes en Argentina (ARSA) estima que el número supera las 4.000 personas.

Diversas investigaciones apuntan que esta migración se encuentra más arraigada entre los varones, al ser los encargados de mantener 
económicamente a su familia extensa. De estructura matrilineal y patrilocal, la familia opera como un sistema económico de prosperidad e intercambios mediante la redistribución de riqueza que circula entre los parientes (Riccio, 2004; Sinatti, 2014). En origen la migración es vista como una estrategia familiar para acumular recursos materiales y simbólicos que mejoren las condiciones de reproducción de los hogares y son tradicionalmente los hijos varones quienes asumen este rol. Entonces, se representa al migrante como "salvador de la familia" y "exitoso" (Zubrzycki, Sánchez Alvarado, 2015). La socióloga senegalesa Fatou Sarr (Daumas, 2014, s/n) sostiene en relación a esto que "hay una dificultad para ser un hombre en nuestro país: el peso de la familia aún recae enteramente sobre sus hombros". Por eso, aunque se registra una tendencia en aumento de la llegada de mujeres, es una migración eminentemente masculina.

Se conforma de varones entre los 20 a los 47 años de edad que en gran medida adscriben al grupo étnico wolof y a la religión musulmana (de las cofradías Mouride y Tidjane principalmente). Su inserción mayoritaria en el comercio responde a factores históricos y culturales entramados en el tiempo, que implosionan en la fase actual del capitalismo, porque los mecanismos migratorios senegaleses tratan de adaptarse a los gajes de la economía capitalista global (Sow, Kokouvi, 2007).

Es menester considerar la intersección entre las redes étnicas, familiares, religiosas y laborales para comprender la recurrencia del comercio, especialmente entre los mourides que se encuentran en Argentina (así como en otros países).

\section{Aproximación a las trayectorias laborales}

La trama de experiencias laborales de los migrantes senegaleses en Argentina muestra dinámicas específicas que nos permiten diferenciar diversos tipos de trayectorias (aquí presentamos sólo dos). También encontramos algunos denominadores comunes, como la inserción inicial en la venta ambulante, la discriminación producto de su hipervisibilización (Morales, 2010) y el racismo institucional (Van Dijk, 2006) en el contexto de arribo.

Si bien el problema a indagar y nuestra etnografía se inician en el espacio de destino de estos migrantes, las variaciones de sus recorridos responden a sucesos del orden laboral y de otros dominios que componen sus biografías, algunos de los cuales transcurren en Senegal y articulan con las experiencias argentinas, conformando subjetividades transnacionales. En origen destacamos la dimensión familiar y migratoria: los casamientos y las visitas de retorno temporarias; en destino destacamos la estatal y la mediática: que incluye la situación regulatoria, el control de su presencia en el espacio público y la construcción de estos migrantes como objetos discursivos. Combinamos 
entonces las miradas prospectivas y retrospectivas en el análisis de trayectorias, en tanto acompañamos algunos procesos durante su desenlace, mientras que otros fueron reconstruidos desde el presente etnográfico indagando hacia el pasado y el futuro (Muñiz Terra, 2012).

\section{La trayectoria de Bamba, desde la venta callejera al local propio}

Bamba llegó a La Plata en septiembre de 2011, con 25 años. Es oriundo de la ciudad de Mékhé, dentro de la "Cuenca del Maní", una región central expulsora de población por su paulatina depresión agroeconómica desde 1960.

Algunos miembros de su familia ya se encontraban trabajando fuera de su país cuando él lo concretó, sobre todo desde la muerte de su padre. Una madre en Estados Unidos, secundada por una hermana y su esposo, un hermano mayor en Italia, y otro con intentos infructuosos de conseguir visados para salir, completan sus parientes más directos. Otra referencia de gran influencia para migrar fue Sokhna, una vecina de su antiguo barrio, a quien también considera familia porque así lo recuerdan sus griots². Ella llegó antes que él a La Plata y de hecho, fue la primera mujer en hacerlo.

Bamba recuerda:

Cuando fue Sokhna a Senegal en el primer viaje fui a la casa de él [hermano de Sokhna, amigo de Bamba], saludé a Sokhna, y después le digo 'me voy a hablar con Sokhna para que me cuente qué hay en Argentina'. Después hablé con Sokhna y ella me dijo 'Argentina sí...los chicos que están allá laburan en la calle, si tenés ganas hasta la noche tenés que llevar un maletín para entrar en el bar, mostrar a la gente, así'. 'Bueno', le digo, 'yo quiero ir, yo quiero ir'. Me dijo 'tengo una persona, si querés vamos juntos te lo voy a presentar, él te puede sacar una visa de Bolivia'. Por eso me presentó a él, hablamos así, le doy mi pasaporte. Dos meses y salió la visa. (Bamba, La Plata, 2016)

Antes de salir de su país, Bamba ya se había trasladado a Dakar como parte de los movimientos migratorios internos (Sakho, 2015), impulsado por el deseo de aventurarse a la capital y aumentar sus propias ganancias económicas con la producción de bijouterie -en oro, plata y aleaciones- que había aprendido a fabricar en el taller de su padre en Mékhé. Su profesión de joyero -fabricante y vendedor- tiene un anclaje étnico y de clase, según el cual en la jerarquía wolof -etnia mayoritaria en Senegal y en la emigraciónlos ñeeño representan un estrato diferenciado a partir de su especialización artesanal y artística, por ejemplo como artesanos de los metales (Ogawa, 2009). A este grupo pertenecen la familia de Bamba y la de Sokhna.

\footnotetext{
2 Estos ejercen funciones relacionadas a la transmisión de los eventos sociales, de la historia familiar, las noticias.
} 
Así, iniciándose en la producción de bijouterie como una tradición sociofamiliar Bamba comenta:

Después de 6 años de laburo, laburo, laburo, me dejó ir [su padre] para vender allá, en Guédiawaye ${ }^{3}$ a casa de Mansour (...). Ahí trabajaba en bijouterie, con Mansour, con el hermano de Mansour, con otros dos más juntamos plata y abrimos un local, para 5 personas, (...) cada uno tenía una mesa y laburábamos para vender afuera, en Dakar Plateau ${ }^{4}$. (Bamba, La Plata, 2016)

Pero las cosas no fueron tan bien como él esperaba así que decidió salir del país.

En bijouterie se ganaba mucha plata, pero después no funcionó más, porque no entraba oro, si querías comprar oro, oro, no podías comprar, y después la gente iba a los países árabes para comprar bijouterie de oro para traer a Senegal, por eso no funcionó más. (...) Tenía menos de 20 años, chiquito, todos éramos chiquitos. (...) En Senegal no trabajé en nada más que bijouterie, solamente bijouterie. (...) cuando viene acá dos años antes, yo me fui a Parcelles ${ }^{5}$, al local de mi hermano. Mi hermano tiene dos locales en Parcelles, y fui con mi hermano más grande (...) después yo me vine acá. (Bamba, La Plata, 2016)

Argumentamos que existe una experiencia previa vinculada a la producción y comercialización de bijouterie, como parte de una crianza moldeada por disposiciones de clase, étnicas y ocupacionales específicas, que sitúa las prácticas de venta de algunos migrantes senegaleses en Argentina como la reterritorialización de una matriz tradicional, condicionada por las lógicas del capitalismo tardío. Este configura un mercado global de trabajo caracterizado por la desregulación, informalización e inequidad en el acceso a puestos de trabajo seguros (Castles, 2013).

Así como Bamba, otros "paisanos" suyos también asumen este conocimiento adquirido en Senegal, que abarca tanto un saber-hacer productivo como de comercialización. Por ejemplo, Laye un compañero de venta de Bamba en La Plata, tras acomodar meticulosamente los productos en su puesto callejero de bijouterie y accesorios, comenta: "tengo memoria, siempre es igual, acá los relojes para la gente pueda mirar, acá billeteras, acá gorras, (...) en Senegal yo era vendedor, por eso cuando vine tenía experiencia para vender, es lo que sé hacer" (Lamb, La Plata, 2016). Asimismo, una mañana en que conversaba con Fall -un referente del colectivo senegalés en la ciudadél me diría "nosotros los senegaleses somos comerciantes" (Fall, La Plata, 2017).

\footnotetext{
Localidad populosa de la región de Dakar.

4 Barrio céntrico administrativo de la ciudad de Dakar.

5 Barrio de Dakar.
} 
Cuando Bamba llegó a Argentina sabía de modo general el trabajo disponible y tras unos días de circular con el maletín, no se adaptó a esta dinámica laboral e identificó una esquina clave para el comercio callejero en La Plata, que se adecuaba mejor a sus expectativas de tener un lugar de trabajo fijo. Se trata de la vereda de la Universidad Nacional de La Plata (ex sede de la Facultad de Humanidades), donde se organizaba una feria que fue creciendo con la adhesión de nuevos vendedores -varios de ellos migrantes limítrofespero que hoy ya no existe.

Ricardo, uno de los feriantes argentinos que compartía el espacio con Bamba, nos contaba los motivos para trabajar allí:

Hace muchos años que trabajo acá en la vereda de enfrente sobre [calle] 7 pero había mucho lío con la municipalidad, entonces uno me aconsejó venirme de este lado porque es territorio nacional, desde esa línea de baldosas negras hacia el Rectorado y Facultad, entonces la municipalidad no puede molestarnos acá, sólo la [policía] federal puede meterse. (Ricardo, La Plata, 2012)

Durante cuatro años Bamba vendió bijouterie en la ochava del edificio universitario. Llegaba alrededor de las 9 de la mañana y armaba su mesa apoyada contra el medidor eléctrico de la vereda, al lado de una parada de taxis. Hacia las 14 horas cuando los feriantes más antiguos desarmaban sus puestos, él ocupaba un espacio sobre un muro bajo del edificio, permitiéndole desplegar un puesto más grande, donde permanecía hasta la caída del sol.

Esta feria fue desarticulada en 2014 con motivo de remodelaciones al edificio universitario, y tras los reclamos de los feriantes el municipio les ofreció un local céntrico bautizado como "Paseo de compras Humanidades" donde se reorganizó la feria. Pero Bamba no quiso mudarse allí, argumentando que "allá no se venden nuestros productos, mejor que no fui, la calle es mejor que Macondo [nombre con que se conoce el local], es un lugar muy chico, no entra mucha gente, y si estuviera ahí tengo que 'aguantar' a la gente que pasa, mira y revisa pero no compra nada, porque la gente va a pasear" (Bamba, La Plata, 2014).

Para ese momento, Bamba se había mudado de casa, dejando la que compartía con Sokhna y sus hermanos desde su llegada al país, ubicada fuera del radio céntrico. Entonces se fue a vivir a un departamento céntrico antiguo compartido con otros senegaleses, algunos migrantes limítrofes y unos pocos estudiantes del interior del país. Allí alquilaba un cuarto para él solo, pero tenía conflictos con algunos compañeros de piso por el mantenimiento del lugar ${ }^{6}$.

\footnotetext{
6 En parte, estos conflictos se relacionan con nuevos roles que los senegaleses asumen en esta etapa. Sinatti (2014) propone que las tareas domésticas experimentadas en la migración son un desafío a la pedagogía de género tradicional de los varones senegaleses.
} 
Entonces, aprovechando estratégicamente las incertidumbres en torno a su lugar de trabajo y vivienda, Bamba emprendió la primera visita de retorno a su familia en Senegal ${ }^{7}$ (Duval, 2002). Los tres meses en origen constituyeron un punto de inflexión en su trayectoria laboral, ya que el tiempo del viaje es una transición durante la cual además del refuerzo de los vínculos sociofamiliares, pudo planificar nuevos movimientos para su regreso a Argentina y comenzó a gestionar los recursos necesarios para concretarlos.

Su regreso a Argentina ofició como inicio de una nueva etapa para acomodar su posición en La Plata y motorizar cambios laborales y residenciales que reorientarían su itinerario. Bamba encontró un nuevo lugar para vender en la ajetreada vereda de la Legislatura provincial y por los contactos generados consiguió alquilar un departamento con otros cuatro amigos senegaleses, al lado de la ubicación anterior y a tres cuadras de su nuevo lugar de trabajo. Allí acondicionó un entrepiso para mantener su habitación privada.

Sin embargo, durante todo este tiempo buscaba concretar otro deseo, el de tener su propio local de bijouterie y accesorios, que condensaba aspectos fundamentales de su proyecto: representaba la aspiración máxima de ser un hombre de negocios que mediante sus emprendimientos en el extranjero se posiciona como un sostén exitoso de su familia en origen.

No obstante, la ciudad de La Plata no era un escenario propicio para esta transición. Por múltiples motivos entre los que Bamba destaca los elevados costos de los locales de alquiler céntricos, la cercanía a otros senegaleses que venden en la calle productos similares, y también su deseo de dejar la ciudad, un lugar de arribo donde lo acogieron sus "paisanos", hizo nuevas amistades y logró reputación entre su colectivo de pertenencia, pero también un territorio de hostilidades, donde experimentó un racismo desconocido y doloroso. Para Bourdieu (2015) la molestia es la experiencia por excelencia del cuerpo alienado que puede encontrarse en las clases oprimidas, y es la que viven muchos senegaleses al trabajar en un contexto de negación histórica e hipervisibilización:

"Nos da mucha vergüenza como nos miran en la calle" (Bamba, La Plata, 2016).

"A veces hay días que yo tengo vergüenza, porque me dicen algo como 'acá es mejor no vender en la calle', dicen 'mirá a los africanos no los pueden sacar'" (Fall, La Plata, 2017).

Estas situaciones reiteradas, Bamba las identificaba de modo exacerbado durante su trabajo estacional en las playas de la costa atlántica, a donde llegaba para aprovechar las oportunidades comerciales que le permitirían acumular

\footnotetext{
7 Él pudo viajar porque tenía la documentación necesaria para ir y venir en condiciones seguras. Sin embargo, este no es el caso de la mayoría de los migrantes.
} 
más recursos económicos. En los preparativos para la temporada laboral del verano de 2016 él decidió cambiar de rumbo y probar suerte en otro escenario que concentrara turistas. Alentado por un primo, fueron juntos a vender en las ferias de festivales de la provincia de Córdoba. En un encuentro que mantuvimos en su nueva ubicación de venta, sobre esto diría que:

A la playa no va más a trabajar, porque ahora para él es más "complicado" porque ahora "entiendo las palabras", lo que habla la gente cuando ellos pasan vendiendo, "son palabras feas", nos cuenta. Elige dejar de ir porque si escucha esas cosas no resistiría pelearse. Comenta que si los chicos pasan ofreciendo sus productos a los bañistas y escuchan y entienden que le dicen cosas discriminatorias reaccionan, se pelean, y él no quiere 'quilombo' [sic]. En cambio, según él en la feria no pasa eso, porque al tener puestos fijos no son ellos quienes se acercan a la gente, sino que es la gente la que pasa y pregunta, "y si hay alguien que molesta le pido que se vaya y listo". (...) Al indagar sobre las palabras con las que se dirigían a él, recuerda que le decían "no queremos tus cosas" o "andate, no queremos nada" (...) "el argentino es maleducado", concluye. (Diario de campo, La Plata, 2015)

A partir de ese verano, Bamba tomó la decisión de mudarse a la ciudad cordobesa de Alta Gracia, donde había trabajado en la Feria de Colectividades y se encontró con un viejo vecino de Mékhé que tiene allí un local propio, lo mismo que dos hermanas de Casamance (sur de Senegal). Allí encontró las posibilidades concretas para abrir su propio negocio de bijouterie y cumplir su deseo de "trabajar tranquilo".

Tras varios meses de circulación y acomodo entre Alta Gracia y La Plata, concretó su mudanza definitiva y la apertura de su local a mediados de 2016. Una condición para esto fue la obtención del Documento Nacional de Identidad argentino, mediante el Régimen Especial de Regularización Migratoria de Extranjeros de Nacionalidad Senegalesa del 2013 (implementado por la Dirección Nacional de Migraciones), que le posibilitó en la práctica acceder a un contrato de alquiler comercial.

De su nueva etapa Bamba reflexiona:

me gusta vivir en Alta Gracia (...) acá estoy mucho más tranquilo que allá, ah....nada que ver, no guardar cosas, no andar con carro, con el frío, con lluvia, iah! Con la municipalidad, con los chorros, gente malo... iAcá es mi negocio! Si entra alguien que no se porta bien, si me molesta, lo voy a tirar a la mierda, afuera. (Bamba, Alta Gracia, 2017)

Consideramos entonces que ciertas representaciones puestas en juego durante el trabajo en la venta ambulante van a ir condicionando las trayectorias laborales y las biografías de estos migrantes. Asimismo, los deseos de mejorar las condiciones de vida propias y del grupo familiar, así como los 
de aventura y autonomía, propician la toma de decisiones en estos procesos. A través de este proyecto Bamba busca iniciarse progresivamente en los estatus de su adultez masculina: convertirse en un proveedor exitoso para su familia de origen y apto para conseguir su primera esposa, preferentemente también en origen.

Mientras concretaba las gestiones necesarias para abrir su negocio en Alta Gracia, Bamba vino a abastecerse de mercadería en Buenos Aires y pasó por La Plata. En esa ocasión comentó "el año que viene si no tengo novia me voy a casar a Senegal porque ya tengo 30 años, quiero tener una familia" (Bamba, La Plata, 2016). Pasado un año de ese encuentro y con su local funcionando, Bamba se casó a la distancia según los preceptos islámicos con una de las hermanas menores de Sokhna, que vive en Mékhé. En febrero de 2018 concretó su segundo viaje de retorno a Senegal para visitar a su esposa y planificar nuevas etapas en su trayectoria laboral y migratoria.

\section{La trayectoria de Billy, de la venta callejera en un circuito interregional a la construcción}

Billy llegó a La Plata en 2007, con 29 años. Proviene de la ciudad costera de Mboro, región de Thiès. Su padre, Papa Gunda, recordaba la elección de vivir en Mboro, por las "ventajas de esta ciudad, que tiene todos los recursos, pesca, agricultura, minería, y posibilidades (...) esta es la región más rica de Senegal" (Papa Gunda, Mboro, 2017).

En esta familia extensa Papa Gunda fue un pionero en migrar fuera del país, siguiendo la tendencia hacia países dentro del continente africano primero y hacia Europa luego (Sakho, 2015). Hoy retornado definitivamente a Senegal, estuvo en su juventud dos años en Costa de Marfil empleado en el rubro textil, luego regresó a Senegal otros dos años a cuidar de la familia en la vejez de su propio padre y se empleó en el sector pesquero en Saint-Louis (193 km al norte, ciudad bañada por el Atlántico y el Río Senegal), para finalmente migrar a Italia en 1990, donde permaneció 25 años interrumpidos sólo por las visitas de retorno a Mboro. En Italia trabajó en diversas fábricas de materiales para construcción, experiencia marcada por un declive de las condiciones laborales.

La trayectoria laboral del padre fue una influencia directa en la conformación de la de Billy, quien se había trasladado de Mboro a Saint-Louis donde compraba pescado fresco en el mercado local y lo transportaba en camión hacia la vecina Mauritania, para revenderlo en mercados locales. Esta actividad fue interrumpida por Papa Gunda, quien dispuso que sus hijos mayores (Billy y un hermano menor) debían salir a trabajar fuera de África, pero no a Europa. Aún en Italia, él mismo vivía las dificultades de un mercado laboral 
en retracción, de la mano de políticas migratorias cada vez más restrictivas. Ya emergía como alternativa una ruta que resonaba bastante en Senegal: países como Brasil y Argentina se posicionaban como los nuevos destinos migratorios.

A los años fuera de Senegal durante los que su padre trabajó para alcanzar la prosperidad familiar, Billy vino a sumarse con su viaje a Argentina, para asegurar el mantenimiento de la misma.

Al llegar a Buenos Aires enseguida obtuvo la información mediante la red de paisanaje de que La Plata era una ciudad donde "se vendía bien y había pocos africanos". Fue así que la eligió para residir y trabajar la mayor parte del año. Allí se insertó en la venta callejera de bijouterie, actividad que llevó adelante durante varios años en un puesto fijo de la Avenida 7, para luego trasladarse diariamente en colectivo con su mercadería a diversas localidades cercanas, donde vendía de manera ambulante, hasta que se hizo de una clientela fija en tiendas locales a las que abastecía con sus productos. Billy completaba su agenda de trabajo con la venta en ferias del calendario de festividades regionales.

A su vez, al año siguiente de su llegada y durante diez años consecutivos partía en enero rumbo a la región Patagónica Central, para vender sus productos en las playas de la ciudad de Puerto Madryn.

El acompañamiento etnográfico a Billy durante dos temporadas en Patagonia nos permitió conocer la dinámica del trabajo estacional que posibilita acumular recursos económicos para la continuidad del proyecto migratorio, mediante la intensificación del trabajo concentrado y la estructuración de redes con vínculos más o menos fuertes que se articulan para este momento. Asimismo, pudimos profundizar en características de su agenciamiento que nos permitieron comprender mejor su posición en Puerto Madryn, dentro de su trayectoria laboral.

Una de estas particularidades refiere a su adscripción religiosa, que lo distingue del resto de los migrantes senegaleses que durante los veranos de 2016 y 2017 llegaron a esa ciudad. Billy era allí uno de los tres musulmanes tidjane y único entre su círculo íntimo. Aunque mourides y tidjanes se reconozcan "hermanos musulmanes", estas pertenencias cofrádicas son importantes en las identificaciones de los sujetos, porque brindan una estructura de referencia, códigos compartidos y cooperación, tanto en origen como en destino. En este sentido, la pertenencia a una cofradía provee una forma de pensarse a sí mismos y a su entorno. Durante los años de trabajar en la costa patagónica, Billy mantuvo en anonimato su condición tidjane. Si bien desde el punto de vista mouride, la pertenencia cofrádica es un recurso que se "usa" públicamente en diversas instancias, los tidjane no parecieran -en los casos estudiados- apelar al aspecto confesional como baluarte para la 
organización. Más bien, como en el caso de Billy, apelan a su carisma y a la acumulación de ciertos capitales, entre los que el social y cultural juegan un rol importante para conseguir el capital económico.

Desde una iniciativa individual Billy fue posicionándose, al punto de sostener todos esos años su exclusividad sobre el valor de Puerto Madryn como destino laboral estacional entre todos los senegaleses que habitan La Plata. Un aspecto relevante a tener en cuenta, si consideramos que saber cuáles son los lugares convenientes para trabajar es un dato que circula de boca en boca y por recomendación. Con esto queremos resaltar que el dominio de la información al interior de las redes migratorias supone un diferencial de poder que incide en la conformación de los vínculos verticales dentro de las mismas y condiciona de diferente manera las trayectorias laborales. Como diría otro vendedor senegalés en estas costas patagónicas, "si más adelante un chico me pregunta dónde trabajaste en el verano, y le digo Puerto Madryn, 'ah!' ya va a querer venir el año que viene, para conocer, tener experiencia, nosotros somos así" (Boubacar, Puerto Madryn, 2016).

El otro aspecto de la agencia de Billy que imprime una particularidad a su trayectoria laboral refiere a su posición de liderazgo (Maffia et alii, 2018) destacada. Él ha construido un activismo con poder de decisión y acción entre su grupo de pertenencia y en posición contestataria hacia el Estado. El proceso de consolidación de un agenciamiento para mejorar las condiciones laborales de los migrantes senegaleses, tanto en Puerto Madryn como en La Plata, se elaboró en una estrategia doble mediante la cual la evocación de lo colectivo fue también una vía para asegurar el bienestar personal.

Hacia 2012 y 2013 en La Plata se dieron situaciones violentas (hostigamiento, detenciones arbitrarias y discurso objetivante de la prensa local) con agentes de control estatal y medios de comunicación hegemónicos, que propiciaron la organización de los senegaleses para denunciarlos. En aquel momento, Billy adoptó un rol protagónico y en diversas instancias de reclamos denunció el racismo institucional, tanto en el Instituto Nacional contra la Discriminación, la Xenofobia y el Racismo (INADI), como públicamente ante la prensa nacional. Así como también supo colocar su preocupación por acceder a sectores más estables y seguros del mercado laboral por fuera de la venta callejera y la necesidad de conseguirlo junto a la regularización migratoria.

En una entrevista para la emisión central del noticiero del canal estatal, Billy decía:

Yo lo que le voy a nombrar es un racismo, te sacan la mercadería, no te dejan trabajar si estás parando cinco minutos, no podés estar todo el día caminando, claro a veces se cansa (...) Es para vivir nomás, pero con un maletín no podés hacer un grande negocio. Hace 5 años que estoy con este maletín no me puedo mover de ahí, no puede avanzar de ahí, pero 
a mí me encantaría tener un trabajo legal, un trabajo en los negocios, pero nadie no me va a tomar como empleado, no tengo documento de Argentina. (Entrevista televisiva, septiembre de 2012)

Para este momento identificamos ciertas movilidades y cohesiones con otros sectores de la sociedad civil que evidencian la complejización de las prácticas contestatarias y de organización de estos migrantes (Espiro, Voscoboinik, Zubrzycki, 2016). Billy comenzó a participar de reuniones en el Centro de Estudios Legales y Sociales (CELS) como representante del colectivo local junto a otro "paisano" y ARSA, para discutir estrategias de defensa de los vendedores senegaleses y la puesta a punto del Régimen Especial de Regularización. Billy prestaba la casa platense donde residía en ese momento y coordinaba las reuniones de discusión e información sobre el programa de regularización en ciernes.

Las experiencias de esa época lo prepararon para enfrentar una situación ocurrida en 2014 en Puerto Madryn, donde, luego de años de trabajar en la ciudad sin mayores sobresaltos, el municipio se negó a otorgarles el permiso de venta a todos los senegaleses que habían llegado ese verano a trabajar. Fue entonces cuando él decidió realizar otra denuncia en la delegación local del INADI, esgrimiendo que se trataba de un hecho de racismo y discriminación, así como también fomentó la visibilidad del caso en los medios de comunicación locales. Con estas estrategias se dilató la resolución del proceso hasta el final de la temporada, mientras que todos los migrantes senegaleses sostuvieron su venta en las playas de Puerto Madryn, sin desaprovechar el esfuerzo que conlleva llegar hasta allí y sin renunciar a las posibilidades de engrosar sus ganancias.

Las experiencias de los años de circulación interregional Buenos AiresPatagonia, y los capitales que Billy acumuló en este recorrido, permiten articular las dos denuncias que llevó adelante como parte del desarrollo de una práctica contestataria. Esto nos obliga a complejizar la posición de este migrante que antes asociábamos a un tratamiento estratégico de cierta información- y reconocerlo como un sujeto reflexivo y con intencionalidades propias desde las que opera para sí y para su grupo de pertenencia (Espiro, Voscoboinik, Zubrzycki, 2016).

"Todos los problemas sabemos que tienen solución, pero en menos de perder tiempo, a pensar en solución. Hay que evitar problemas. Yo para mí, por lo menos, es lo que digo. Ayer un chico africano vino a hablar conmigo y le dije 'primero en la vida hay que buscar el trabajo, cuando le tienen fijo, ahí sí, hay que buscar el placer, pero no puede tener placer sin tener trabajo, si no te vas a arruinar el futuro'", le recomendaba Billy a un paisano suyo (Billy, La Plata, 2017). 
Su posición como referente senegalés fue solicitada en diversas instancias, como las sucesivas reuniones con organizaciones estatales y civiles de defensa de los derechos de los migrantes. Porque el hostigamiento hacia los vendedores senegaleses lejos de cesar se sostuvo en el tiempo, y sus mecanismos se volvieron cada vez más violentos, física y simbólicamente.

En esta coyuntura, a inicios de 2017 en Buenos Aires y en La Plata se dieron una serie de conflictos que obligaron a estos migrantes a redefinir sus estrategias laborales. Por un lado, el desalojo de los "manteros" en el barrio porteño de Once que desplazó a los senegaleses a trabajar a otros lugares, entre ellos La Plata, agudizando la competencia por los recursos laborales locales en un contexto ya conflictivo con el municipio. En esta situación, los senegaleses que vivían y trabajaban en dicha ciudad ensayaron nuevas estrategias para preservar su posición. Durante ese año en La Plata se dio un proceso por el que muchos de estos migrantes comenzaron a "dejar" la venta en la calle, para incorporarse al mercado de la construcción, a través de la Unión Obrera de la Construcción de la República Argentina (UOCRA).

Nuevamente, Billy participó sucesivamente de reuniones con diversos organismos, para que actúen como intermediarios con la Municipalidad, por un lado, y con la UOCRA, por el otro, como vías alternativas para estabilizar su situación laboral. En una reunión mantenida en la delegación de la Secretaría de Derechos Humanos de Nación sostenía:

si podemos tener contacto para estar bien con la UOCRA, está bien, algunos no tienen capital para tener un local en feria, también los que tienen capital para tener un local en feria le metemos ahí, los que no pueden se van en la UOCRA, dividirnos para organizarnos bien para que dejamos la calle. (Billy, La Plata, 2017)

La nueva estrategia contestataria de Billy, desde la cual se abrió paso en el mercado de trabajo argentino y delineó su trayectoria laboral, fue poner en práctica un capital diferencial recurriendo a la representación de sí y de su grupo de pertenencia como "profesionales", al contar con especialidades que los hacen trabajadores capacitados, aptitudes que veía diluirse en los mecanismos de oferta laboral existentes en la UOCRA -nos referimos al sistema de bolsas de trabajo. Es entonces cuando él actualizó sus experiencias laborales en origen: "tengo el registro de Senegal, camionero soy, pero todavía no lo pude sacar en Argentina y generalmente casi todos los chicos tenés profesionalidad (...) Yo tengo también la profesión acá de montador, yo soy diplomando" (Billy, La Plata, 2017).

Así como veíamos con Bamba como la experiencia de discriminación se corporizaba en sus años de venta callejera, Billy tampoco escapó a este proceso y desde su propia subjetivación comentaba: "estamos sufriendo en la calle, a 
veces me da vergüenza como yo estamos hace muchos años, siempre el mismo laburo, me da pena, por qué no me puede progresar" (Billy, La Plata, 2017).

Luego de varios meses de participar en las asambleas de la UOCRA, durante días en los que suspendía su venta y veía cómo alguno de sus "paisanos" quedaba seleccionado para algún trabajo, mientras él participaba de sucesivas reuniones para encontrar formas de aumentar esta selección, finalmente en junio de 2017 obtuvo un contrato de empleo en una obra ferroviaria mediante el sindicato. Esto interrumpió su circuito de trabajo entre La Plata y Puerto Madryn, durante el lapso del contrato laboral.

Sin embargo, con la intervención de la delegación sindical de La Plata a fines de 2017, los abusos de la patronal se hicieron sentir, con sueldos mal liquidados, accidentes laborales sin intervención de la ART o rechazos de la residencia precaria como documento habilitante para contratarlos. Siguiendo a Castles (2013), el recrudecimiento de las políticas migratorias, que va de la mano de los procesos de reestructuración de la fuerza de trabajo, producidos desde la crisis global de 2008, empujan a los trabajadores migrantes hacia empleos inseguros y explotadores, también en Argentina.

Mientras tanto la dimensión asociativa que caracteriza a este grupo migratorio (Maffia et alii, 2018), emergió como exigencia en el contexto local y frente a las demandas estatales de un interlocutor "válido" (de acuerdo a la misma lógica estatal) comenzó la organización formal de la "Asociación Senegalesa de La Plata" que tiene a Billy como vicepresidente.

Esta trayectoria, con fuerte activismo y liderazgo comunitario en el contexto argentino, no lo desligó de su proyecto migratorio vinculado a la dimensión familiar. Mientras Papá Gunda administra el hogar en Mboro con el dinero que envían sus hijos desde Argentina, Billy concretó el casamiento a la distancia con su segunda esposa, una vez que el capital económico y social adquirido a partir de su nuevo trabajo en la construcción se lo permitieron.

\section{Reflexiones finales}

La reconstrucción de las trayectorias laborales de Bamba y Billy permite reflexionar sobre algunas cuestiones centrales en relación al fenómeno de la migración senegalesa transnacional en la región, así como abre la puerta para repensar las políticas de la diferenciación y alteridad en las ciudades contemporáneas.

En primer lugar, nos posibilita sopesar la centralidad del comercio callejero en las etapas iniciales de las trayectorias laborales de estos migrantes. Actividad a la que se accede por las redes migratorias y que, por un lado, permite poner a jugar un saber hacer con el que se cuenta desde origen; por otro, en sectores desfavorecidos del sistema económico global, permite trabajar 
con poco capital inicial y poco dominio del idioma local; finalmente, dada la matriz de interlocución racista (Van Dijk, 2006), es la opción laboral posible, al ser escasos los sectores alternativos para la inserción de estos migrantes.

Sin embargo, en los itinerarios laborales observamos que la venta callejera constituye un momento en las trayectorias, caracterizadas por transiciones rápidas que derivan en otras prácticas laborales y representan la posibilidad de movilidad social por medio del trabajo autónomo o asalariado.

En la retrospectiva encontramos elementos que permiten comprender estas transiciones y puntos de inflexión. Para ello fue menester considerar que los recorridos laborales son interdependientes de otros dominios que organizan el curso de vida de estos sujetos, que se despliegan a través de las fronteras. Observamos que la familia ocupa un lugar central, desde el momento de la planificación del proyecto, hasta su mantenimiento, así como las movilidades, en forma de circuitos de trabajo estacional, o visitas de retorno temporarias a Senegal. Asimismo, también moldean estas trayectorias ciertas representaciones y prácticas puestas en juego durante el trabajo en la venta callejera, como la imagen de prestigio que buscan sostener los migrantes, o los discursos mediáticos y el control estatal que buscan contrarrestarla.

Finalmente, a partir de los aspectos aquí abordados debemos referirnos al carácter translocal en el que se despliegan estas trayectorias laborales. Consideramos que su desarrollo es eminentemente transnacional en tanto las trayectorias están insertas en proyectos migratorios de base familiar, en los cuales el trabajo de los miembros emigrados es la base del sostén de los hogares en origen, gracias a las remesas en forma de dinero, regalos e inversiones que aquellos ponen a circular y cuyo éxito depende, en gran medida, de las capacidades desarrolladas para "saber-migrar". Otro aspecto de esta dimensión familiar lo constituyen los matrimonios consumados a través de las fronteras, a los cuales los migrantes acceden cuando han acumulado ciertos capitales que los posicionan como candidatos aptos (que asimismo dependen de las posiciones alcanzadas en el ámbito laboral), y por los cuales reafirman su adultez. Claramente, en el devenir de estas trayectorias laborales transnacionales inciden tanto los condicionamientos objetivos que constriñen el accionar de estos migrantes, como así también los procesos decisorios a partir de los cuales estos agentes le imprimen un rumbo propio.

Debido al espacio disponible, no hemos podido ahondar aquí en las expectativas futuras que toda trayectoria laboral contempla por definición, así como tampoco en la dimensión micro del transnacionalismo, palpable a nivel de las acciones y pautas cotidianas. No obstante, ambos aspectos son profundizados en nuestra investigación. 


\section{Referencias bibliográficas}

ARAB, Chadia. La circulation migratoire: une notion pour penser les migrations internationales. e-migrinter, n. 1, p. 20-25, 2008.

CASTLES, Stephen. Migración, trabajo y derechos precarios: perspectiva histórica y actual. Migración y Desarrollo, v. XI, n. 20, p. 8-42, 2013.

DAUMAS, Cécile. Interview á Fatou Sarr: Au Sénégal, les femmes gouvernaient. Libération. 2014. Disponible en: <http://www.liberation.fr/planete/2014/05/26/ au-senegal-les-femmes-gouvernaient_1027383 > . Acceso en: 30.07.2016.

DUVAL, David. The return visit-return migration connection. In: HALL, Michael; WILLIAMS, Allan (eds.). Tourism and Migration: New Relationships between Production and Consumption. Dordrecht: Kluwer Academic Publishers, 2002, p. 257-276.

ELDER, Glen. Life course: sociological aspects. In: SMELSER, Neil; BALTES, Paul (eds.). International Encyclopedia of the Social and Behavioral Sciences. Oxford: Elsevier, 2001.

ESPIRO, M. Luz. Representaciones de los africanos entre los habitantes de la ciudad de La Plata a partir de la circulación de "los vendedores bijouterie". Kula. Antropólogos de Atlántico Sur, n. 7, p. 53-66, 2012.

ESPIRO, M. Luz. Entre la trama y el drama. Discursos mediáticos sobre inmigrantes senegaleses en La Plata. In: MATTA, Juan Pablo (comp.). V Jornadas de Antropología Social del Centro: antropología social y mundos posibles en transformación. Tandil: Universidad Nacional del Centro de la Provincia de Buenos Aires. Facultad Ciencias Sociales, 2016a, p. 1613-1633.

ESPIRO, M. Luz. De Buenos Aires a la costa chubutense: una aproximación etnográfica a la movilidad estacional de migrantes senegaleses. In: DE CRISTÓFORIS, Nadia; NOVICK, Susana (comps.). Jornadas. Un siglo de migraciones en la Argentina contemporánea: 1914-2014. Ciudad Autónoma de Buenos Aires: Universidad de Buenos Aires. Instituto de Investigaciones Gino Germani - UBA, 2016b, p. 867-886.

ESPIRO M. Luz; VOSCOBOINIK, Sonia; ZUBRZYCKI, Bernarda. Enfrentando el racismo institucional. Análisis de dos casos de migrantes senegaleses en argentina (2012-2016). REMHU, Revista Interdisciplinar da Mobilidade Humana, v. 24, n. 48. p. 63-78, 2016.

FALL, Papa Demba. Sénégal: Migration, marché du travaille et développement. Suisse: OIT, 2010.

INDEC. Censo Nacional de Población, Hogares y Viviendas 2010. Disponible en: $<$ http://www.indec.gob.ar/>.

LEVITT, Peggy. Los desafíos de la vida familiar transnacional. In: Grupo Interdisciplinario de Investigador@s Migrantes (coords.). Familias, niños, niñas y jóvenes migrantes: rompiendo estereotipos. Madrid: IEPALA-Caja Madrid Obra Social Casa Encendida, 2010, p. 17-30. 
LUCERO, Marcelo F. Trayectorias laborales y reconversión de una agroindustria en un contexto local. In: $6^{\circ}$ Congreso Nacional de Estudios del Trabajo. Buenos Aires, 2003.

MAFFIA, Marta et alii. Formas organizativas y liderazgo entre migrantes africanos subsaharianos recientes. Migraciones Internacionales. Reflexiones desde Argentina, n. 3, p. 9-28, 2018.

MORALES, Gabriel. Nuevas dinámicas migratorias globales y representaciones locales sobre los negros en Argentina. El caso de las percepciones de agentes de la Policía bonaerense sobre recientes migrantes africanos. Sociedad y discurso, n. 18, p. 121-148, 2010.

MUÑIZ TERRA, Leticia. Carreras y trayectorias laborales: una revisión crítica de las principales aproximaciones teórico-metodológicas para su abordaje. Revista Latinoamericana de Metodología de las Ciencias Sociales, v. II, n. 1, p. 36-65, 2012.

OGAWA, Ryo. Pour une meilleur compréhension de la structure sociale des Wolofs. Journal of Asian and African Studies, n. 78, p. 113-130, 2009.

RICCIO, Bruno. Transnational mouridism and the Afro-Mouslim critique of Italy. Journal of Ethnic and Migration Studies, n. 30, p. 929-944, 2004.

ROBERTI, Eugenia. El enfoque biográfico en el análisis social: claves para un estudio de los aspectos teórico-metodológicos de las trayectorias laborales. Revista Colombiana de Sociología, v. 35, n. 1, p. 127-149, 2012.

SAKHO, Papa et alii. A emigração internacional senegalesa: das casas no campo ás ciudades litorâneas. In: HERÉDIA, Vania (org.). Migrações internacionais: O caso dos senegaleses no sul do Brasil. Caxias do Sul: Belas-Letras, 2015, p. 23-49.

SINATTI, Giulia. Masculinities and intersectionality in migration: transnational Wolof migrants negotiating manhood and gendered family roles. In: TRUONG, Thanh-Dam et alii (eds.). Migration, Gender and Social Justice. Alemania: SpringerOpen, 2014, p. 215-227.

SOW, Papa; KOKOUVI, Tete. Estalvis populars Africans a Catalunya: Tipus i formes submergides de pràctiques financeres dels immigrants. Barcelona: Fundació Jaume Bofill, 2007.

VAN DIJK, Teun A. Discurso de las élites y racismo institucional. In: BASTIDA, Manuel Lario (coord.). Medios de comunicación e inmigración. Murcia: CAM, 2006, p. 15-36.

ZUBRZYCKI, Bernarda; SÁNCHEZ ALVARADO, Lina. Redes y proyectos migratorios de los senegaleses en Argentina. Cadernos CERU, v. XXVI, n. 1, p. 69-84, 2015. 